\title{
Burnout, Moral Distress, and Job Turnover in Critical Care Nurses
}

\author{
Brooke A. Whittaker ${ }^{1}$, Deborah R. Gillum ${ }^{1} \&$ Judith M. Kelly ${ }^{2}$ \\ ${ }^{1}$ Bethel College School of Nursing, Mishawaka, Indiana, USA \\ ${ }^{2}$ Consultant in Curriculum \& Educational Programming, Texas Women's University, Denton, Texas, USA \\ Correspondence: Samuel P. Abraham, Associate Professor of Nursing, 1001 Bethel Circle, Bethel College School \\ of Nursing, Mishawaka, Indiana, 46545, USA.
}

Received: November 11, 2018

Accepted: November 26, 2018

Online Published: November 30, 2018

doi:10.20849/ijsn.v3i3.516

URL: https://doi.org/10.20849/ijsn.v3i3.516

\begin{abstract}
Nurse turnover, shortages, and lack of nurse retention have all been linked to stress among nurses. This ethnographic study explored if burnout and moral distress, often a result of excessive stress, led to job turnover among critical care nurses in northern Indiana and southern Michigan. It also explored the factors that may cause burnout and moral distress in the identified population. Although burnout and moral distress have been studied in various professions and locales over the years, research specific to critical care nurses has been limited in the northern Indiana, southern Michigan area. In this study, 100\% of the nurses felt that burnout and moral distress led to turnover. These same nurses attributed burnout and moral distress to affecting the quality of care given to patients. The guiding framework for this study's design was Corley's theory of moral distress.
\end{abstract}

Keywords: moral distress, burnout, stress, critical care nurses, job turnover

\section{Introduction}

High stress levels among nurses can lead to job dissatisfaction, moral dilemmas, absence of staff engagement, burnout, and emotional fatigue (Corley, 2002). Although this same stress may positively contribute to individuals gaining more focus, it may also lead to feeling pressured and being overwhelmed (Moss, Good, Gozal, Kleinpell, \& Sessler, 2016) resulting in insomnia, fatigue, irritability, anxiety, and depression (Moss et al., 2016). In turn, this stress can contribute to burnout and moral distress, which may lead to nurse turnover and staff shortages within the nursing field.

Today's nurses experience increased demands in a constrained environment, including high patient acuity, technological advances, staffing shortages, shorter patient lengths of stay, and financial pressures. These factors contribute to high stress levels (Kurtzman \& Corrigan, 2007). When nurses experience job-related stress, the likelihood of effectively managing patient care becomes difficult (Lang, 2008). Society has viewed nurses as having a caring persona; however, if nurses suffer from stress, burnout, or fatigue, they become insensitive to patient situations, needs, and the needs of their families (Young, Derr, Cicchillo, \& Bressler, 2011). This stress can be detrimental to patient care and lead to further physical issues for the nurse, including depression or even substance abuse (Young et al., 2011).

Stress, moral distress, or even burnout in the workplace is often unavoidable. Stress can present itself in many different forms, affecting each individual differently. Stress levels can be contingent on a nurses' education level, years of experience, and training (Lawrence, 2011). Novice nurses are thought to have higher stress levels than expert nurses. However, some nurses may suggest that nurses with several years in the profession have the collective weight of distressing experiences that lead to ones' moral distress over time (Elpern, Covert, \& Kleinpell, 2005).

\section{Statement of the Problem}

In everyday healthcare experiences, nurses play a vital role in contributing to health and wellness (Joint Commission on Accreditation of Healthcare Organizations, 2002, p. 5). However, nurses have an extreme amount of stress within the profession which affects job satisfaction, recruitment, and retention within the field (Corley, 2002). The current and growing shortage of nurses in the United States represents a serious threat to the quality of health care (Lawrence, 2011). Due to many changes in the health care environment, nurses have more responsibilities and are expected to do more with less and keep up to date with advanced and sophisticated 
technology, such as computerized charting systems, which leads to increased stress, fatigue, and burnout (Corley, 2002). Burnout in nurses leads to reduced personal accomplishment, emotional exhaustion, and depersonalization (Patrick \& Lavery, 2007). Critical care nurses are among the highest stressed nurses in the profession (Moss et al., 2016). Often this stress is related to quick overturn in patients; maximum accountability; technological advances; high role expectations; repeated exposure to sorrow, pain and death; management of end of life care; duration or mandated work hours; and conflicts related to patient care within the critical care units (Hurst \& Koplin-Baucum, 2005). Although previous research has identified factors that affect overall nursing turnover, additional research in specific areas of nursing and locales is needed before factors may be generalized to the nursing profession.

\section{Purpose of the Study}

The purpose of this study was to determine if moral distress and burnout contribute to turnover among critical care nurses in northern Indiana and southern Michigan, and if so, what factors were involved. The findings can be used to increase understanding of critical care nurse turnover and help reduce stress in the critical care areas. Prompts included:

$>$ Can you describe a time when you experienced burnout? Explain.

$>$ What contributed to your feeling of burnout? Explain.

$>$ Are you currently experiencing burnout? If so, how long have you been experiencing burnout?

$>$ As a critical care nurse, please tell me more about your experiences with burnout.

\section{Literature Review}

To explore the published research on this topic, keywords including stress, burnout, and moral distress were used in CINAHL and Medline databases. The search was further narrowed by limiting to articles written in English, and only articles published between 2002-2017. One search included critical care nurse stress, resulted in 71 articles, six of which were pertinent to the proposed research. The next search included moral distress in critical nurses, resulted in 68 articles, of which seven were applicable. Burnout in critical care nurses resulted in 100 articles; however, only four were pertinent to this study.

Corley who created a model for moral distress, based her research around Jameton's definition of moral distress (Corley, 2002). Jameton, a researcher of moral distress in nursing practice, defined moral distress and distinguished the difference between initial and reactive moral distress in 1993 (Corley, 2002). He described initial moral distress as "frustration, anger, and anxiety when faced with institutional obstacles or conflict with others about values" (Corley \& Minick, 2002). Jameton further explained that reactive distress is when nurses cannot act on their initial distress (Corley \& Minick, 2002). Corley stated that moral distress was a major problem among nurses and was common among those who work in areas of insufficient staffing, inadequately trained staff, and work with organizational policies and procedures that make it difficult for nurses to meet facility demands (Corley, 2002). Therefore, Corley developed the moral distress model to validate reliability within her research.

Moral distress causes nurses to act in a manner contrary to their personal and professional values (Elpern et al., 2005). Nurses who care for patients who require aggressive care and prolonged life measures were thought to have the highest level of moral distress (Elpern et al., 2005). In 2004, the Association of Critical-Care Nurses $(\mathrm{AACN})$ advised that every nurse and employer investigate and address the harmful effects moral distress has on the nursing profession. Detrimental effects of moral distress include loss of self-worth, effects on personal relationships, psychological effects, behavioral manifestations, and physical symptoms leading to burnout (Elpern et al., 2005).

Burnout was first identified in the 1970s as a work-related group of symptoms that occurred in people with no psychological or psychiatric disorder (Moss et al., 2016). Burnout has recently become a worldwide phenomenon among high stress professionals, especially in the health care setting (Moss et al., 2016). Symptoms include frustration, anger, fear, anxiety, inability to feel happy, unprofessionalism, feeling overwhelmed, hopelessness, lack of empathy and feelings of being insufficient at work (Moss et al., 2016). Physical symptoms of burnout can include exhaustion or fatigue, insomnia, muscle tension, headache, and gastrointestinal problems (Moss et al., 2016). Severe symptoms were found in $33 \%$ of critical care nurses, and up to $86 \%$ had at least one of the three classic symptoms (Moss et al., 2016).

Burnout is common among critical care nurses when compared to other fields of nursing (Moss et al., 2016). Among critical care nurses, $73 \%$ experience emotional exhaustion, $60 \%$ lack personal accomplishment, and $48 \%$ 
experience depersonalization (Moss et al., 2016). Those individuals least likely to experience burnout were the extraverted, conscientious, and agreeable personality types. Moss et al. reported that the long-term consequences of burnout include post-traumatic stress disorder (PTSD), alcohol abuse, and substance abuse. Symptoms of PTSD surface in approximately $29 \%$ of critical care nurses and up to $18 \%$ of these nurses meet the diagnostic criteria of burnout. Of the nurses with PTSD, $98 \%$ had symptoms consistent with burnout. End-of-life care, feeling overextended, combative patients or families, visualization of open wounds or extreme bleeding, and postmortem care have all been identifiable sources associated with PTSD (Moss et al., 2016).

\subsection{Empirical Literature}

Moral distress occurs when a nurse is unable or feels unable to advocate for a patient (Corley, 2002). Nurses who experience this type of distress are likely dissatisfied with their work, avoid patient care, or even leave a position or the profession. (Corley, 2002). In turn, more than 35\% of nurses in one study stated they were considering leaving the hospital, which increased the turnover rate (Mosadeghrad, 2013). The researchers further stated that $30 \%$ of nurses with this distress left their nursing positions within the first year of employment, and $57 \%$ by their second year, which is higher than the national average of 21.3\% reported in 2000 (Bowles \& Candela, 2005). Inadequate pay, work inequality, feeling overworked, being short staffed, job insecurity, and lack of support by upper management were significant sources linked to these stressors (Mosadeghrad, 2013). Intensive care units experience annual turnover rates between 13\% and 20\%, while the United States average in 2013 for all types of employees was $10.4 \%$ (Moss et al., 2016). The annual cost to replace one critical care nurse was estimated at $\$ 65,000$ (Moss et al., 2016).

Moral distress and burnout negatively impact work engagement (Lawrence, 2011). Critically important to effective job performance, work engagement involves a positive and fulfilling work-related state of mind that is characterized by commitment and perseverance (Schaufeli, Salanova, González-Romá, \& Bakker, 2002). Work engagement occurs when an organization has nurse empowerment through effective leadership at all levels within the organization (Bowles \& Candela, 2005).

Some nurses manage stress by reflecting on experiences (Lawrence, 2011). Being able to reflect enhances nurses self-esteem and improves nursing practice (Gustafsson, Asp, \& Fagerberg, 2007). However, the inability to manage and reflect on stress can lead to further issues with moral distress and burnout. In some intensive care units, physicians, nurses, fellows, and advanced practice providers hold regular staff debriefings on challenging end-of-life cases with ethics and palliative care consultants, social workers, and patient representatives (Pastores, 2016). This reflective practice provides an avenue to de-escalate stressors. The literature suggests that healthcare leaders or hospital administrators should initiate innovative ideas to promote team building outside one's work environment to promote better patient outcomes and staff morale (Moss et al., 2016).

\subsection{Theoretical Literature Review}

Corley's moral distress model assesses the reliability and validity of moral distress as it relates to nursing as a moral profession, and nurses as moral agents (Corley, 2002). The concept behind this framework is to understand how moral distress and burnout affects nurses in the critical care areas. Psychological effects of moral distress can cause anger, frustration, anxiety, helplessness, powerlessness, compromised integrity, grief, and sadness (Corley, 2002).

Elpern et al. (2003) conducted a study using Corley's theory on moral distress using 28 staff nurses in a medical intensive care unit at Rush University Medical Center in Chicago. Nurses identified situations such as caring for patients who were not expected to benefit from aggressive care as a frequent concern associated with moral distress (Elpern et al., 2003). This study concluded that moral distress has implications that extend beyond job satisfaction and retention and further studies should be developed and tested to decrease this problem in the critical care settings (Elpern et al., 2003).

Burnout was found to be associated with job turnover, reduced patient satisfaction, and decreased quality of care (Moss et al., 2016). Burnout affects mental and physical well-being of healthcare workers in the critical care field (Moss et al., 2016). Diminishing the effects of burnout in the critical care areas is important not only to the healthcare worker but also for the well-being of patients (Moss et al., 2016).

Job turnover is related to absenteeism, aggression, hostility in the workplace (Mosadeghrad et al., 2013). In one study, $26 \%$ of employees graded their job stress as high, identifying inadequate pay, inequality at work, too much work, staff shortage, lack of recognition and promotional prospects, time pressure, lack of job security and lack of management support as reasons associated with their stress (Mosadeghrad et al., 2013). With a threat to quality of work life, job stress related positively to employees' intentions to quit (Mosadeghrad et al., 2013). 
In an ethnographic study, the goal is not to find, but understand the truth (Baxter, 2012). In the current study the purpose was to hear, interpret and understand what is happening in the nursing profession and to better understand the events leading to moral distress and burnout (Baxter, 2012). The Corley moral distress model could offer new options to those who confront ethically challenging situations which lead to nurse turnover and moral distress (Baxter, 2012).

\subsection{Summary of the Literature Review}

A review of the literature revealed there is a knowledge gap specific to moral distress and burnout among critical care nurses. Although moral distress and burnout are well known in many professions, these areas have not been recognized as a true problem in the nursing profession, as evidenced by increasingly high turnover rates. Burnout and moral distress are underlying causes associated with nurse turnover (Corley, 2002). This study explored burnout and moral distress in critical care nurses in northern Indiana and southern Michigan and the factors contributing to nurse shortage or turnover.

\section{Theoretical Framework}

Corley identifies her theory using a model for moral distress (Corley, 2002). In this model she studies nurses, patients, and the organization where one practices. This model defines nurses as moral agents and nursing as a profession. Corley believes moral distress, suffering and residue impact the patient, the nurse, and the organization. Corley's model identifies areas that impact the care given by the nurse, and the pain and suffering they feel from difficult situations.

Categories from Corley's model of moral distress address nurses who believe care was "not in the patient's best interest" (Baxter, 2012). These issues include following a family's wishes when a patient has a "do not resuscitate" order, medical orders given for unnecessary testing that would not change outcomes, and treatments that prolong pain and suffering (Baxter, 2012). Corley believes that the moral concepts that define a nurse are comprised of commitment, sensitivity, autonomy, sense making, judgement, conflict, competency, and certainty therefore, when a nurse feels violated moral distress occurs overtime (Corley, 2002).

A qualitative exploratory approach was used to research this topic in twelve intensive care unit (ICU) nurses. The literature suggests three themes in forming a foundation for moral distress or ethical dilemmas: nurses' personal mindsets of moral beliefs, the nurses' experiences, and the nurses' decision-making processes (McLeod, 2014). Burnout was acknowledged by Maslach and Jackson (as cited in Meltzer \& Huckabay, 2004) as emotional exhaustion (apathy or loss of concern), depersonalization (negative attitudes toward care), and diminished personal accomplishment (evaluates oneself negatively). This study solely investigated moral distress and burnout among critical care nurses in northern Indiana and southern Michigan area as they relate to job turnover.

\subsection{Conceptual Definitions}

Moral distress is classified as a psychological disequilibrium that occurs when the ethically right course of action is known but cannot be acted upon (Elpern et al., 2005). Burnout syndrome is defined by three classic symptoms: exhaustion (fatigue), depersonalization (distant or indifferent attitude toward work), and reduced personal accomplishment (tendency to negatively evaluate the worth of one's work) (Moss et al., 2016). The independent variables for this study were moral distress, burnout, and job turnover. The dependent variable was the nurses' responses to moral distress and burnout.

\subsection{Operational Definitions}

Critical care or intensive care nurses were defined as registered nurses who worked on a unit caring for hemodynamically unstable patients were frequently requiring ventilator assistance or possibly life support measures. The intensive care nurses were responsible for the hemodynamically unstable patients that required extensive monitoring for life threatening conditions. Participants in this study related with the symptoms of exhaustion, fatigue, indifferent attitude, reduced personal accomplishment, depression, insomnia, irritability, agitation, quitting, anxiety were identifying with burnout and moral distress.

\section{Methodology}

This ethnographic research study explored burnout and moral distress as it affected critical care nurses in southern Michigan and northern Indiana. Multiple measures were used to gather descriptive, in-depth information regarding the presence of burnout and moral distress and factors causing the stressors. Results from survey questions guided follow-up phone or in-person interviews. The interviews enabled the researcher to critically explore beyond the surface level information, especially identifying emotions, views, and experiences 
that tell critical stories about burnout and moral distress. The data collected was used to describe the presence of burnout and moral distress, as well as stress causing factors, among the critical care nurses in northern Indiana and southern Michigan. The research investigated the following questions: Does moral distress and burnout lead to turnover in critical care nurses? How do factors leading to turnover differ? Is there a difference between nurses in northern Indiana and southern Michigan?

\subsection{Sampling}

A convenience sampling method, using a snowball technique, was used to obtain a sample of participants from 12 critical care nurses. These nurses either work 7a.m. to 7p.m. or 7p.m. to 7a.m. in ICU. The inclusion criteria required an Associate (ADN) or Bachelor of Science in Nursing (BSN) with more than one-year experience as a critical care nurse. Potential limitations could include a small sample size, sample homogeneity, or reluctance to discuss these potentially sensitive topics.

The sample for the study included six critical care nurses from southern Michigan and six critical care nurses from northern Indiana. Nurses were purposely selected based on their background and experience. The researcher previously knew certain individuals who met the researchers' defined inclusion criteria and those individuals were able to recommend others to participate in the study. The researcher then reached out to those individuals who willingly participated in the research.

\subsection{Research Setting}

The setting for this research included northern Indiana and southern Michigan. The setting for the interview was conveniently chosen by the participant and free from distractions. The interviews took place on the telephone or in person. Most nurses were more inclined to participate in this study on the phone or in a setting convenient for them and not during regular working hours. After verbatim transcription of the interview, the researcher contacted the participants to ensure key assumptions were consistent with the information recorded during the initial interview and to ask a few additional clarifying questions.

\subsection{Ethical Considerations}

Consent to participate in this research was completed after permission was granted from the College Institutional Review Board. All participants in the research were given an informed consent form to complete prior to a survey. If a phone interview was the chosen method for interviewing, the researcher obtained consent prior to the phone interview by fax or cellular device. The recorded conversations were stored on the researcher's secured iPhone. This information was backed up on the researcher's computer to ensure the information was available at all times and to safeguard the data from potential loss. This computer is password-secured, and this method ensured the information was stored safely and maintained the confidentiality of the participants. Upon completion of the study, all data and informed consents will be saved for 3 years, after which the data will be deleted and shredded. This process will ensure and maintain the confidentiality of the participants used in this study. Completion of the NIH training course on protecting human research participants was acquired by the researcher.

In the event a participant was distressed during the interview process, the participant could be referred to the Employee Assistance Program available through their employer. Chaplains are available for all staff members and available on sight 24 hours a day, 7 days a week.

\subsection{Instrument}

This ethnographic study used a brief survey tool and qualitative interviewing to gather desired information. The interview used open-ended, guiding questions, based on a review of the literature, to address the presence of burnout and moral distress among critical care nurses, to identify factors causing stress, and describe personal experiences and scenarios relating to burnout and moral distress. To help participants make informed decisions concerning the specific differences between burnout and moral distress, definitions of each stressor were included on the prompts. These questions were used to give direction to individual interviews.

\subsection{Data Collection Process}

The data was collected from 12 day or night shift critical care nurses with more than one-year experience. The study was conducted when the participant was available either in person or on the phone, day or night. The participants were informed of the study and confirmed that they met the criteria. The researcher did not express any bias, nor use intimidation, and did not contaminate any data during interaction with participant by giving verbal or non-verbal cues. The researcher recorded the conversations with permission of the participant as outlined on the informed consent. Each interview was transcribed verbatim and lasted approximately 60 minutes 
to 2 hours. The researcher also made notes of nonverbal cues during the interviews to assist with the data analysis.

Once surveyed, the researcher analyzed the data to identify patterns and themes within the data. These patterns were distinguished through the questions answered and the observations made during the interview process either through verbal communication, body language, or tone of voice. If the interview was by phone, lack of body cues could be a limitation, however, the tone of ones' voice cued into further questioning or inquiries. These commonalities or similarities among the participants helped identify patterns and areas of concern.

\subsection{Data Analysis}

Coding the data included recording the interview, taking handwritten notes, transcribing the interviews verbatim using Word and condensing and identifying patterns or themes within the information. Once the patterns were identified, they were highlighted from the written information gathered and listed on $3 \times 5$ cards to clearly identify or visualize all characteristics or themes related to this study. Once patterns were clearly identified in this process, themes became more evident. Themes identified, isolated, or verified the patterns gathered from the data collection process. Descriptive statistics were used to describe the sample.

\section{Results}

This ethnographic research study asked the following questions: Does moral distress and burnout contribute to turnover among critical care nurses in northern Indiana and southern Michigan? If so, what factors cause moral distress and burnout among these critical care nurses? The findings of this study support Corley's model of moral distress which suggests that moral distress causes burnout and turnover in the nursing profession.

\subsection{Demographics}

This study included six nurses from northern Indiana and six nurses from southern Michigan (see Table 1). These nurses, each Caucasian, worked twelve-hour day or night shifts. Two male nurses and ten female nurses from an intensive care unit were studied. Ages ranged from 27 years old up to 71 years old. The mean average age of the participants was 50 years old. Years of nursing experience varied from 3 to 43 years of general nursing experience. The critical care experience varied from 2 years to 43 years. The mean average critical care experience was 18.7 years. The six nurses from southern Michigan all worked in a Level 1 Trauma, Magnet status hospital. The six nurses from northern Indiana worked in a Level 2 Trauma hospital. Four of the nurses were ADN or BS nurses, six were BSNs, and two were MSNs.

This study was able to identify how burnout and moral distress could potentially lead to turnover in critical care nurses. Themes and patterns were identified with per facility (hospital) and per nurse, regarding burnout, moral distress as it related to patients or nurses, and the nurses' future intentions.

Table 1. Demographics

\begin{tabular}{lcc}
\hline \multicolumn{1}{c}{ Variable } & Frequency & Percentage \\
\hline Gender & 2 & \\
$\quad$ Male & 10 & $17 \%$ \\
Female & & $83 \%$ \\
Region: & 6 & $50 \%$ \\
$\quad$ Indiana, USA & 6 & $50 \%$ \\
$\quad$ Michigan, USA & & \\
Ethnicity: & 12 & $100 \%$ \\
$\quad$ Caucasian & & \\
Highest Level of Education: & 4 & $33 \%$ \\
ADN & 6 & $50 \%$ \\
BSN & 2 & $17 \%$ \\
MSN & & \\
\hline
\end{tabular}

\subsection{Facility Burnout}

Burnout as it related to the facility was identified by violence or verbal abuse, call-ins, mandated shifts, staffing, support from management, and average turnover rates. Violence or verbal abuse was experienced by $92 \%$ of nurses. Fifty percent of nurses admitted to missing work shifts due to burnout or morally distressing situations. One hundred percent of the nurses who were mandated shifts attributed their burnout to the additional shifts. 
Southern Michigan nurses felt supported by management (100\%) however, only $17 \%$ of nurses in Indiana felt supported by management, which attributed to their burnout.

One hundred percent of nurses from northern Indiana stated that staffing ratios were unsafe; contributing to both moral distress and burnout because the staffing affected the quality of care, they were able to give their patients. One hundred percent of the nurses stated that staffing contributed to their burnout. Participants in this study cited an average turnover rate from 1 to 4 years in northern Indiana and 1 to 6 years in southern Michigan. They cited nurse resignation, reduction of work hours, early retirement, and retooled qualifications, such as returning for a master's degree or a professional refocus as changes.

\subsection{Nursing Burnout}

Burnout from a nursing stand point was identified as mental and physical health, physical strain of the job, and work-life balance. One hundred percent of the nurses stated that they had experienced some type of physical or mental strain from the job that contributed to burnout and/or turnover. Physical strains that were noted were back and knee pain, cervical fusions, and myocardial infarctions. Thirty-three percent of southern Michigan nurses stated that they had adequate work-life balance, whereas only 17\% of northern Indiana nurses stated they had adequate work-life balance.

\subsection{Moral Distress and Patients}

Moral distress, as it related to patients, incorporated end-of-life situations, lack of resources, nurse to patient ratios, and quality of care. One hundred percent of the nurses stated that end-of-life care contributed to their burnout. Ninety-two percent of these nurses stated that they lacked the resources needed to do their job. One hundred percent of Michigan nurses believed nurse-to-patient ratios were safe, even with the current staffing issues. However, $100 \%$ of Indiana nurses felt nurse-to-patient ratios were unsafe with current staffing issues. One hundred percent of the nurses stated that burnout and moral distress affected the quality of care they provided to their patients.

\subsection{Moral Distress and Nurses}

Moral distress, as it related to nurses, encompassed coping, desensitization, charge nurse responsibilities, and recommendations for improvement. Fifty-eight percent of nurses exercised, 58\% drank alcohol, and $42 \%$ self-medicated as methods of coping with their burnout or moral distress. Ninety-two percent of nurses admitted to being desensitized by certain patient populations. One hundred percent of the charge nurses in this study contributed being in charge to their burnout. The most common recommendation from the nurses was to improve staffing issues. Although Corley did not focus on burnout, these same issues impact moral distress and turnover in critical care nurses.

\subsection{Other Contributing Factors}

Various factors, described in the Discussion section of this thesis, contributed to burnout and eventual turnover of the critical care nurses. The participants cited exhaustion and alienation due to mandated extra shifts, staff shortage and increased responsibilities and tasks, high patient nurse ratios, violence and verbal abuse, lack of support from management, lack of resources, and inexperienced and incompetent associates as contributing factors that led to turnover. Although participants at each facility agreed with most contributing factors, differences existed in two areas: mandated shifts which extended work hours and support from management. The southern Michigan nurses reported fewer mandated shifts and better support from management, which may have attributed to more satisfactory working conditions.

\section{Discussion}

Themes and patterns were identified with numerous examples of nurse and patient situations. Participants were very excited to share their stories. For some, the refection from these stories helped to identify with their own levels of burnout and moral distress. Some nurses were surprised how they scored themselves after learning what burnout and moral distress consisted of and how it related to their personal nursing practice. Nurses rated their burnout between 0-10, 10 being the worst level of burnout.

\subsection{Burnout Ratings}

The nurses rated their burnout between a 3 and 10 with an average mean of 5.8. Nurses from southern Michigan had scores ranging from a 3 to 7 with a mean of 5. Nurses from northern Indiana had scores between 4 and 10 with a mean of 6.7. Northern Indiana nurses scored themselves higher on the burnout scale. 


\subsection{Moral Distress Ratings}

Moral distress was ranked in the same fashion and overall nurses ranked their scores between 3 and 9 with an average mean of 5.9. Nurses in southern Michigan ranked between 3 and 6.5 with a mean of 5.3, whereas nurses from northern Indiana ranked between 5 and 9 with a mean of 6.3. Again, nurses from northern Indiana scored themselves higher on the moral distress scale. A major factor in these ratings was attributed to managerial support.

\subsection{Facility Burnout}

Facility burnout themes were identified as the following: violence or verbal abuse, call-ins, mandated shifts, staffing, support from management, and average turnover rates on the floor. Ninety-two percent of nurses stated that they had experienced violence or verbal abuse from patients or family members.

\subsection{Violence}

During this study, an Indiana nurse reported that she was punched in the mouth by a patient. One Michigan nurse reported that her burnout stemmed from "unappreciative people or people that are argumentative with no resolution. They are just lashing out at you and you just have to take it." Another Indiana nurse reported that a family fired every nurse for a different reason. "Trying to figure out staffing and accommodate family without making them feel like they can dictate the care they receive without support from management is difficult. Our manager suggested that I take the patient and be in charge to smooth things over and have a good night. In this situation the family did not have validity to why the previous nurse should not be taking care of the patient. I had to transport patients to computed tomography scan (CT), respond to codes, and rapid assessment team (RAT) calls. The doctor that rounded on the patient the next morning made comments to the family about dictating which nurses should be taking care of the patient and even went on to say we can't have a trauma hospital without an ICU and we can't have an ICU run by new grads and travelers. He wanted to dictate that no travelers or new grads could care for his patients (in front of family), but we don't have the resources. He needs to go talk to someone because it is affecting the care. These doctors are not willing to stand up for the nurses until after the fact. I feel that the doctors don't know or don't pay attention to that stuff, to what is really going on here. They look at beds and not at staffing and they fill the beds regardless of what the staffing looks like."

In Michigan, a nurse reported while taking care of a prisoner who had a police officer with him, the patient broke loose, smashed a window out and attacked the police officer. The 60-year-old officer was assaulted and almost lost his gun. Hospital security tasered the patient. Distraught family members of the patient were hostile with the nurse after the incident. An Indiana nurse stated she had a patient with multiple comorbidities and the family was accusatory and aggressive towards the staff and in denial of the health condition of the patient. These family members were coming to the hospital under the influence of alcohol and other drug paraphernalia. She stated "it was difficult to take care of the patient when you feel that you are under the gun in a sense. Everything is the fault of the staff, even though the patient made poor choices throughout their life. The family wanted all the names of the staff that took care of their family member. I felt angry, of course we want to do the right thing, but that situation made us feel like we intentionally hurt people and they wanted to place blame. Security was called to assist. They were also videotaping the staff and were allowed to do so per Risk Management, which put us in a vulnerable position. There's a lot wrong with that situation. It was a high-profile case and it was creepy." Another Indiana nurse reported a patient's spousal abuse and stopped the husband from seeing the patient. The husband later followed the nurse and threatened her. After this incident, hospital security had to walk her to her vehicle after her shifts.

\subsection{Call-Ins}

Fifty percent of nurses stated they have called-in because of feeling burned out. The numbers were an even split between Michigan \& Indiana nurses that called in. One Indiana nurse stated, "I'm afraid of losing my job. I have too many points and there's nobody there. We support each other and work as a team." Another Indiana nurse stated, "I called off a lot more for mental health breaks. I wasn't sick. I just needed a break." One Michigan nurse reported that she called in on multiple occasions because of burnout. She stated, "I even told my manager that I'm calling in tomorrow because I need a mental health day. They were supportive." One Indiana nurse reported that she did call in several times but stated "if I'm not here, everyone else will suffer burnout; and it isn't safe. Nurses are too new to understand what is really going on or how it should be."

\subsection{Mandated Shifts}

Mandated shifts contributed to burnout among Indiana nurses. Nurses in northern Indiana stated that they were mandated at least two extra shifts per 6-week schedule, though only $17 \%$ of those nurses stated that they had an 
adequate work-life balance. The $17 \%$ that stated they had adequate work-life balance was a result of decreasing ones' hours from 72 to 60 to compensate for those mandated hours. Additionally, these nurses can work extra shifts for monetary incentives. Nurses in southern Michigan stated that they were not mandated extra shifts but were able to pick up to receive incentives. Approximately 33\% of these nurses stated that they had a good work-life balance. One Michigan nurse stated "flexibility in scheduling is important here." She was able to schedule all of her days in a row and have a week off to be with her family. Both facilities used travel nurses to compensate for the nursing shortages.

\subsection{Staffing}

Staffing was a concern with all nurses when it came to burnout. One-hundred percent of the nurses stated that staffing contributed to burnout. One hundred percent of the nurses in northern Indiana stated that the nurse to patient ratios were unsafe due to their current staffing issues. According to one Indiana nurse, "RNs are under a lot of stress to care for the patient, but it is not a priority for the hospital to make staffing number one. When you are in charge and have to take patients because there is not enough staff, it gets old after a while. Patients who should be 1:1 are doubled up, the 2:1 patient to nurse ratio is rare, and 3:1 is more common recently because of nurses leaving from burnout." According to a Michigan nurse, staffing ratios are a safe 2:1 patient to nurse ratio. However, Michigan nurses did not feel it was safe when a nurse was placed on call for the ICU and could be mandated to staff any unit in the hospital. "One time I was floated to Pediatric Intensive Care Unit (PICU). The hospital thinks because I am a critical care nurse, I can float anywhere, there is a big difference between PICU and Medical Intensive Care Unit (MICU). I really want to say, I don't want to do this because it is jeopardizing my license, but I don't want to rock the boat." The nurses in southern Michigan stated that staffing ratios remained safe despite staffing issues. Michigan nurses reported staffing was always 2:1, and sometimes 1:1, when appropriate. This was attributed to having a strong management or leadership team.

\subsection{Management}

Support from management played a huge role in burnout. Eighty-three percent of nurses in northern Indiana did not feel supported by management within the hospital. However, $100 \%$ of nurses felt supported by management in southern Michigan. Management in Michigan consisted of a Chief Nursing Officer (CNO), a director, a manager, a day and night shift coordinator, day and night shift educators, and a charge that never takes patients. "Our manager will jump in and help out, cover lunches, help transport patients and does whatever she needs to do. The unit coordinators will be in charge, so charge can take over with patients and help. I feel very supported." In Indiana, their management team consists of the $\mathrm{CNO}$, no director, a manager, no unit educator (only hiring coordinator) and a charge nurse that takes patients more often than not. According to an Indiana nurse, "I address safety issues with them, crisis moments that are beyond unsafe, unsafe staffing ratios and management doesn't come in. Charge nurses are expected to transport patients to CT in the morning, respond to codes, RAT calls, take patients, help out on the unit, and find staff for the next shift." Another Indiana nurse reported, "Having three patients, you don't have time to think through things like you normally would, its' frustrating, they do staffing for rooms versus for staff, it's a bad thing." According to another Indiana nurse, "This unit is bleeding nurses, you just can't transfuse nurses, you must give them a reason to stay, pay more, not mandate overtime or on call shifts, decrease the number of staff meetings, overwhelming Facebook and texts or bathroom posts about work updates and needs, it's irritating."

\subsection{Turnover}

Fifty-eight percent of nurses believed that the average turnover in their unit was approximately 1-2 years. One hundred percent of the nurses from northern Indiana stated that the average turnover was between 1 and 4 years. Southern Michigan nurses stated the average turnover was between 1 and 6 years. Turnover was attributed to nurses being burned out and quitting, re-tooling or going back to school, decreasing hours or retiring.

\subsection{Nurse Burnout}

Burnout specifically focused around mental and physical health, physical strain of the job and work-life balance. Eighty-three percent of the nurses stated that they were fatigued from working. For example a Michigan nurse stated "we work long and busy days with no break, no lunch and nurses tend to put the needs of their patients ahead of their own needs. By the end of the day, I am really tired. I have a long drive home, but I am exhausted. I don't have energy for anything or anyone else." Sixty-seven percent were exhausted both mentally and physically. An Indiana nurse stated that her fatigue and exhaustion were due to staffing ratios not being appropriate for ICU and being forced to work mandated shifts in addition to getting texts everyday about staffing. Sixty-seven percent of nurses had insomnia related to their job. "Sometimes I am thinking about something that happened at work, and it creates part of my insomnia." Another nurse stated, "Everyone else is on a dayshift 
routine, phones ringing, people up in the house doing activities. It's hard to sleep." Eighty-three percent of nurses were more irritable. One Michigan nurse stated, "My irritation comes when experience doesn't matter anymore. They take people right out of school and run them through the program. Now you are a critical care nurse. People think they know, but they don't know. You should have basic nursing med-surg or cardiology before you come to an ICU. This way they have some experience before they step in to take care of critical patients." Sixty-seven percent of nurses felt overwhelmed. One Indiana nurse reported, "There are times I feel that patients are not getting the care they need. You come back on shift to a patient who has respiratory issues, and there isn't even a suction set up. Oral care kits are still full that you left in the morning, and no pillows are in the room to turn the patients. Nurses are busier because of extra tasks put on them such as changing beds constantly, due to not using Foleys. Low infection rates come with a trade. Nurses are so busy that they aren't doing chores or tasks. They are forgetting the basics."

One hundred percent of the nurses stated that they have experienced some type of physical strain or injury from the job, which in turn contributed to their burnout or turnover. Numerous nurses reported back pain issues. One nurse reported that she could have worked longer rather than retire; however, 12-hour shifts along with the physical wear and tear on the body after a while "takes a toll." She stated, "The hospital floor, the surface, takes a toll on your knees, hips, and feet after a while." Work-life balance was difficult for night shift nurses, especially for those nurses that were mandated to work extra shifts. One nurse stated, "Frustration occurs when you work nights. It incorporates two days, not just one because you lose the next day as well." Those nurses who had flexible scheduling options reported more work-life balance.

\subsection{Patient Related Moral Distress}

Moral distress was characterized by patient-related moral distress and nurse-related moral distress. Moral distress with patients centered on end-of-life care, unfortunate patient cases, lack of resources, nurse to patient ratios, and quality of care. End-of-life (EOL) care was mentioned frequently when exploring the cause of moral distress. One hundred percent of the nurses studied stated they felt that end-of-life care was the number one reason behind job turnover. This moral distress involved "keeping patients alive that are basically dead and family wants all things done. All vasopressors and lifesaving drips are going and there's nothing else we can do. A patient's insides are dying, a patient smells of death and we are keeping them alive. This makes me not want to work in a place like this. We keep adding medications and we are doing more harm to the patient because we must honor the families wishes," per one Michigan nurse. Another frustration came from nurses who could not make their patients comfortable during end-of-life situations either because of the wishes of the family, or because the patient's blood pressure and respiratory status were compromised. "We can't give medications to make them comfortable because it will depress their breathing more but there is zero chance they will survive this. They insert chest tubes, arterial lines, do lab draws that make them hurt, and that causes me moral distress."

Other frustrations came from family members changing a code status from what the patient wanted. Nurses reported moral distress due to keeping a patient alive so that the family could come to see the patient before they died. A Michigan nurse stated, "We put families in a position to make these decisions when they shouldn't sometimes because they feel like they are killing their family member. Back in the days, physicians told the families we have nothing more to offer, we need to make your family comfortable at this time and the care would shift to comfort care or do not resuscitate (DNR). Now terminal patients are put on dialysis (or other treatments) none of that is comfortable for the dying patient. We tie them down when they try to pull their tube out because they are done with their life and we stop them. We have families that request more and more treatment. Just because you can do something doesn't mean you should. We do that a lot."

Some nurses noted that certain patient cases that were tragic caused them moral distress. Reflections from Indiana nurses described situations where unfortunately the person was in the wrong place at the wrong time. This nurse stated, "Unfortunately, the act of God or fate put one woman in a bad storm. She pulled to the side of the road, and a tree fell on her car, and now she's a quadriplegic. She will never be able to hold her one-year old baby. As a parent, the whole situation is so horrific you feel empty inside. You want to do what you can, but you know you can't do anything to make her situation better. You care more in these situations, you do the personal best you can. You feel their pain, you find a way to cope. We deal with war-zone like situations. I too suffer from PTSD at times and sought counseling for this continued stress. Innocent patients are ones I appreciate taking care of."

Another Indiana nurse reflected on the case of a woman that was 9 months pregnant and cardiac arrested, she had a large pulmonary embolism (PE). "Medics did cardiopulmonary resuscitation (CPR) in route, the obstetrics and gynecology physician (OBGYN) surgically extracted a crying baby. When the husband came back to see his 
wife, it was difficult to watch and she died. The new father did not address the baby at that time; however, three days later he went home with the baby. It was hard, hard just thinking about what that baby is going to miss out on."

In a child abuse case, an Indiana nurse reported to Child Protective Services (CPS) that a child stated that her grandparents abused her and her siblings. "They asked me if it was safe to send this patient home and follow up tomorrow. I felt it was safe, so the patient was sent home. CPS interviewed the children in the home with the grandparents and nothing came of it. One month later, one of the children was beaten to death by the grandmother's son or father of the child. Obvious injuries to the children were found. They had cigarette lighter burns and lots of scars. The older two children were tied to chairs and were beaten, and the 15-year-old took the brunt of the abuse. The 8-year-old drew attention away from the brother and ended up being the one that was killed. I live with this now."

Some nurses noted forming special bonds with patients, especially when the patients came back into the hospital for chronic problems beyond their control. "I took a trauma patient. We were very busy. I was a new nurse. I looked around the room and saw a picture of someone I went to high school with. I was in shock. I felt comfortable to tell his mom I knew him. I bonded more with her then. I prayed with her. I was not religious, but spiritual. He ended up in a nursing home; he was a traumatic head injury patient. He came back and forth to ICU for multiple complications over the next couple years. I took care of him due to our bond. Three or four years later, was his last admission here. He died one evening. His mom wanted a lock of his hair. I got the hair, I cried with mom. I share this bond with his mom. We keep in contact on Facebook."

\subsection{Nurse Related Moral Distress}

Nurse moral distress focused on desensitization, responsibilities of being in charge, coping mechanisms, and recommendations for improvement. Ninety-two percent of nurses stated they had become desensitized towards certain patient populations. Some nurses reported being desensitized by patients that were "repeat offenders," such as alcoholics, overdose patients or even diabetic ketoacidosis patients (DKAs). Ten of the twelve nurses studied were charge nurses. One hundred percent of the charge nurses stated that they became more burned out because of being in charge. During this study, two Indiana nurses stepped down from the charge role, one reduced hours and the other resigned. One Indiana charge nurse reported "we are constantly short staffed and spread thin, we need more resources than we have, just knowing colleagues are frustrated and there is only so much we can do, asking them to do more than they should, leads to burnout but there is no way around it. We need to find the safest solutions possible, but we have to do what we have to do and sometimes that means we put our licenses on the line when we take assignments that are not safe." A Michigan nurse stated, "I feel most overwhelmed when I am in charge of the unit. Multiple admissions, multiple patients circling the drain, some that may require intubations, arterial line placement, you're needed in six different places at once. I just have to take a deep breath and utilize the resources we have."

\subsection{Coping Mechanisms}

The nurses used different coping mechanisms to deal with their burnout and moral distress. Fifty-eight percent of nurses admitted to drinking alcohol as a coping mechanism. Fifty-eight percent did some type of exercise or physical activity to decrease stress. Forty-two percent self-medicated with prescribed, non-prescribed or over the counter medications. Others described situations when they used sarcasm or inappropriate humor to cope with certain patient situations.

\subsection{Lack of Resources}

Ninety-two percent of nurses stated that they lacked the resources needed to do their job. Outside of nurse staffing, some reported lack of resources to provide grief counseling. Nurses also reported lack of items such as computers, medications from pharmacy, simple items such as a blood pressure cuffs or a pulse ox, or even a lack of (helpful) nursing assistants. Nurse to patient ratios affected nurses' moral distress in nurses from Indiana. Indiana Nurses reported feeling that the quality of care was not adequate because of the ratios. "Sometimes you just don't have time to deal with things when you can't be effective because you just don't have time. Not having the time to deal with what is important is the problem."

\subsection{Future Plans}

Future plans of these nurses included staying where they were, re-tooling and going back to school, decreasing their hours, intentions on quitting or currently applying for another position, or planning for an early retirement. Currently, only one out of the twelve nurses foresaw themselves staying in their current position greater than three years. One nurse from northern Indiana resigned her position during this study. Another northern Indiana 
nurse changed from full-time to per diem status. Another northern Indiana nurse changed her hours from 72 to 60 per pay period. Two nurses retired early from Michigan during this study. Three nurses were going back to school for an advanced nursing degree. One Indiana nurse plans to return to school for a law degree. Of those four nurses burnout and moral distress were cited as reasons behind going back to school. One hundred percent of these nurses believed that both burnout and/or moral distress had led to turnover in their units and affected the quality of care they gave to their patients (see Figure 1).

\subsection{The Model for Burnout, Moral Distress and Turnover}

The Model for Burnout, Moral Distress, and Turnover is used to identify how burnout and moral distress contributes to nurse turnover. Moral distress contributed to burnout and eventually led to turnover of some nurses. However, other nurses had moral distress that directly led to their turnover. Other nurses stated that burnout directly led to the turnover. Nurses were able to identify how a collaboration of moral distress and burnout over time also led to turnover. The turnover is identified as an end result in the model; however, it continues with the cycle outlined as the constant turnover caused the burnout in some cases. The model identifies different aspects of how burnout, moral distress, and turnover impacted nurses.

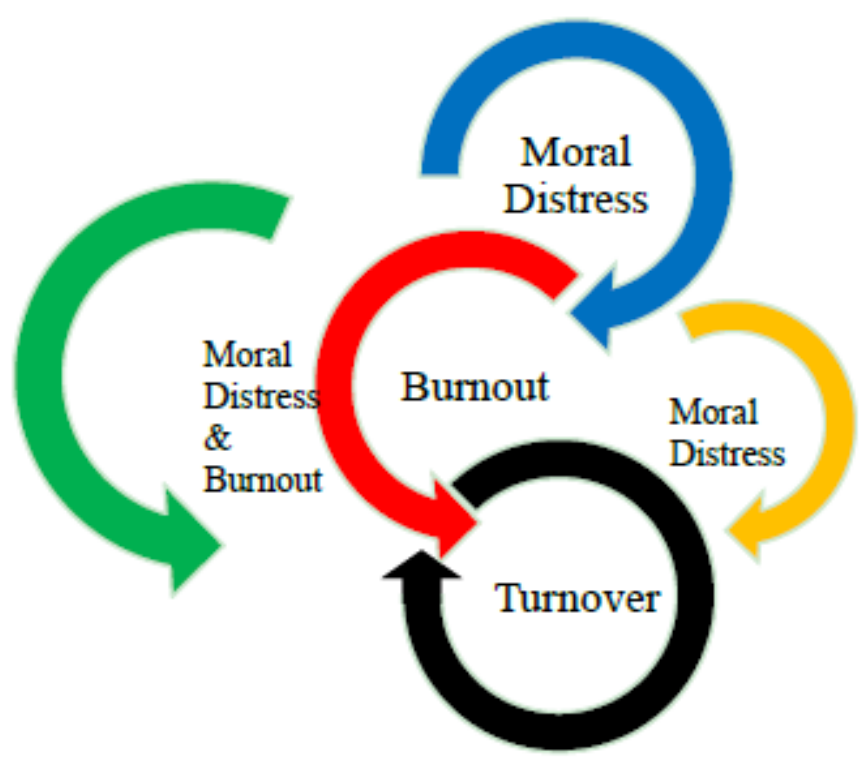

Figure 1. Model for burnout, moral distress \& turnover

\section{Limitations}

Study limitations included a small sample size of twelve Caucasian participants. Two participants were male, the other ten participants were female. Gender viewpoints may be different. Initial inclusion criteria were to only allow BSN prepared nurses. Due to the overwhelming number of nurses who wanted to participate in the study, ADN prepared nurses were added to the study after IRB approval was granted, to allow for a more diverse population. These ADN participants had the most experience in the profession. Some nurses who wanted to participate and share their stories had to be turned down due to fulfilling the sample size of twelve participants. This was an unanticipated limitation to some degree and may have allowed for a larger sample size. Some participants experienced confusion on the difference between burnout and moral distress. Other limitations would include the inability to read body language over a phone interview. Limitations would include inexperience of the researcher conducting a research study. This topic was the researchers' first area of study.

\section{Implications for Nursing}

The findings from this research study have the potential for being significant for nursing professionals. The data collected, including the stories of personal experiences with burnout and moral distress, should strengthen the existing pool of knowledge related to burnout and moral distress in the nursing profession and may decrease turnover and improve overall job satisfaction for nurses. Nurse empowerment happens through managerial 
support and is effective to a successful workforce and engagement.

\section{Recommendations}

\subsection{Participant Recommendations}

Recommendations given by all nurses were to have appropriate staffing. Indiana nurses also recommended safe nurse to patient ratios. In the United States, only fourteen states have regulations on appropriate nurse to patient ratios. Indiana and Michigan do not have state regulated laws in place for nurse staffing ratios (American Nurses Association, 2018).

One hundred percent of the nurses stated that reflecting or discussing work-related situations with colleagues would help improve burnout and moral distress. Colleagues who have non-medical spouses found it difficult to confide with them, unless they were in the medical field. Nurses who had spouses in the medical profession found it helpful to talk with their spouse. Some Indiana nurses recommended adding a gym membership to their employee wellness programs, free of charge, as a healthy way to deal with stress. Considering that $58 \%$ of nurses coped by exercising, 58\% coped by drinking alcohol and $42 \%$ of nurses self-medicated, the option is a valid recommendation. Michigan nurses stated their facility offered a discounted fitness membership, as long as the gym membership was utilized twice a week, membership was greatly discounted at $\$ 20$ a month. Indiana nurses paid a discounted rate of $\$ 40$ a month. Michigan managers and physicians contributed towards moral boosting situations such as nurses' weeks, holidays, and high census days with luncheons and dinners that boosted morale for both day and night shifts. Indiana managers contributed at times, to high census days, however, nurses were expected to contribute to their own carry-ins on nurses' weeks, holidays, and high stress weeks for morale boosting.

\subsection{Researcher Recommendations}

As the researcher, recommendations would suggest a state regulated nurse to patient ratio would be appropriate. Intensive care units should be regulated at a 1:1 or 2:1 patient to nurse ratio. Under no circumstances should nurses be expected to take three ICU patients. Increased support on safe nurse to patient ratios from physicians and surgeons in northern Indiana is recommended. Michigan physicians and surgeons were supportive towards safe nurse to patient ratios. Northern Indiana hospitals staffing to beds and not to nurses is a problem. Increased or more competitive wages for Indiana nurses should be investigated, as the average new graduate nurse wage starts at approximately \$6-7 more an hour in Michigan than in Indiana. Benefit packages need to be improved, including better tuition reimbursement, specifically in ICU, to retain staff. Both facilities might also consider providing a free gym membership if a staff member commits to two days a week, to improve mental and physical health of their employees. According to the research, managerial support impacted staff tremendously between both groups. Michigan nurses felt supported due to a well-staffed, supportive chain of command (including educators) on both shifts. Indiana nurses would benefit tremendously by following this same pattern. This research suggests that appropriate staffing ratios, leadership, staffing, mental and physical wellness need to be further investigated. Quantitative studies including variables, relationships, and interactions could also be further studied.

\section{Acknowledgment}

The authors would like to express their appreciation and gratitude to all nurses who willingly participated in the study.

\section{References}

American Nurses Association. (2018). Nurse staffing: States with staffing laws. Retrieved from https://www.nursingworld.org/practice-policy/advocacy/state/nurse-staffing/

Baxter, M.L. (2012, January). Being certain: Moral distress in critical care nurses. BeingCertain, 95.

Bowles, C., \& Candela, L. (2005). First job experiences of recent RN graduates. Journal of Nursing Administration, 35(3), 130-137. https://doi.org/10.1097/00005110-200503000-00006

Corley, M.C. (2002). Nurse moral distress: A proposed theory and research agenda. Nursing Ethics, 9(6), 636-650. https://doi.org/10.1191/0969733002ne557oa

Corley, M.C., \& Minick, P. (2002). Moral distress or moral comfort. Bioethics Forum, 18(1-2), 7-14.

Elpern, E., Covert, B., \& Kleinpell, R. (2005). Moral distress of staff nurses in a medical intensive care unit. American Journal of Critical Care, 14(6), 523-530.

Gustafsson, C., Asp, M., \& Fagerberg, I. (2007). Reflective practice in nursing care: Embedded assumptions in 
qualitative studies. International Journal of Nursing Practice, 13(3), 151-160. https://doi.org/10.1111/j.1440-172X.2007.00620.x

Hurst, S., \& Koplin-Baucum, S. (2005). A pilot qualitative study relating to hardiness in ICUnurses: Hardiness in ICU nurses. Dimensions of Critical Care Nursing: 24(2), 97-100. https://doi.org/10.1097/00003465-200503000-00011

Joint Commission on Accreditation of Healthcare Organizations. (2002). Health care at the crossroads: Strategies for addressing the evolving nursing crisis. Nursing Forum, 46. Retrieved October-December, 2011, from http://www.aacn.nche.edu/media/pdf/JACHO8-02.pdf

Kurtzman, E.T., \& Corrigan, J.M. (2007). Measuring the contribution of nursing to quality, patient safety, and health care outcomes. Policy, Politics \& Nursing Practice, $8(1), \quad 20-36$. https://doi.org/10.1177/1527154407302115

Lang, K.R. (2008). The professional ills of moral distress and nurse retention: Education an antidote? American Journal of Bioethics, 8(4), 19-21. https://doi.org/10.1080/15265160802147181

Lawrence, L.A. (2011). Work engagement, moral distress, education level, and critical reflective practice in intensive care nurses. Nursing Forum, 46(4), 256-268. https://doi.org/10.1111/j.1744-6198.2011.00237.x

Meltzer, L., \& Huckabay, L. (2004). Critical care nurses' perceptions of futile care and its effect on burnout. American Journal of Critical Care, 13(3), 202-208.

McLeod, A. (2014). Nurses' views of the causes of ethical dilemmas during treatment cessation in the ICU: A qualitative study. British Journal of Neuroscience Nursing, 10(3), 131-137. https://doi.org/10.12968/bjnn.2014.10.3.131

Moss, M., Good, V.S., Gozal, D., Kleinpell, R., \& Sessler, C.N. (2016). An official critical care societies collaborative statement: Burnout syndrome in critical care healthcare professionals: A call for action. Critical Care Medicine, 44(7), 1414-1421. https://doi.org/10.1097/CCM.0000000000001885

Mosadeghrad, A.M. (2013). Occupational stress and turnover intention: Implications for nursing management. Health Policy and Management, 1(2), 169-176. https://doi.org/10.15171/ijhpm.2013.30

Pastores, S.M. (2016). Burnout syndrome in ICU caregivers: Time to extinguish! Chest, 150(1), 1-2. https://doi.org/10.1016/j.chest.2016.03.024

Patrick, K., \& Lavery, J.F. (2007). Burnout in nursing. The Australian Journal of Advanced Nursing: A Quarterly Publication of the Royal Australian Nursing Federation, 24(3), 43-48.

Schaufeli, W.B., Salanova, M., González-Romá, V., \& Bakker, A.B. (2002). The measurement of engagement and burnout: A two sample confirmatory factor analytic approach. Journal of Happiness Studies, 3(1), 71-92. https://doi.org/10.1023/A:1015630930326

Young, J.L., Derr, D.M., Cicchillo, V.J., \& Bressler, S. (2011). Compassion satisfaction, burnout, and secondary traumatic stress in heart and vascular nurses. Critical Care Nursing Quarterly, 34(3), $227-234$. https://doi.org/10.1097/CNQ.0b013e31821c67d5

\section{Copyrights}

Copyright for this article is retained by the author(s), with first publication rights granted to the journal.

This is an open-access article distributed under the terms and conditions of the Creative Commons Attribution license (http://creativecommons.org/licenses/by/4.0/). 